\title{
Article
}

\section{Developing the organisational culture in a healthcare setting}

Nightingale, Adele

Available at http://clok.uclan.ac.uk/21493/

Nightingale, Adele (2018) Developing the organisational culture in a healthcare setting. Nursing Standard, 32 (21). pp. 53-63. ISSN 0029-6570

It is advisable to refer to the publisher's version if you intend to cite from the work. http://dx.doi.org/10.7748/ns.2018.e11021

For more information about UCLan's research in this area go to http://www.uclan.ac.uk/researchgroups/ and search for < name of research Group>.

For information about Research generally at UCLan please go to http://www.uclan.ac.uk/research/

All outputs in CLoK are protected by Intellectual Property Rights law, including Copyright law. Copyright, IPR and Moral Rights for the works on this site are retained by the individual authors and/or other copyright owners. Terms and conditions for use of this material are defined in the policies page.

\section{CLoK}

Central Lancashire online Knowledge www.clok.uclan.ac.uk 


\section{Organisational Culture in Healthcare}

\section{Keywords}

Culture, organisational culture, healthcare delivery, theoretical framework, leadership

\section{Aim and intended learning outcomes}

The aim of this article is to enable nurses to understand the powerful role of organisational culture in influencing the effectiveness of healthcare delivery, primarily within the British National Health Service (NHS). After reading this article and completing the time out activities, you should be able to:

Describe what organisational culture is within a healthcare setting through an examination of various theoretical frameworks.

Understand the role of organisational culture and its importance in influencing effective healthcare delivery.

Reflect on some of the steps that can be undertaken to improve organisational culture in the healthcare setting.

\section{Relevance to The Code}

Nurses are encouraged to apply the four themes of The Code: Professional Standards of Practice and Behaviour for Nurses and Midwives to their professional practice (Nursing and Midwifery Council (NMC) 2015). The themes are: Prioritise people, Practise effectively, Preserve safety, and Promote professionalism and trust. This article relates to The Code in the following ways:

Nurses are enabled to practise effectively by being aware of the power and role of organisational culture in influencing healthcare delivery.

The Code states that nurses should act in partnership with those receiving care, helping them to access relevant information and support when they need it. By examining organisational culture, the underpinning values and beliefs, which should encompass patient- 
centred care, and working in partnership with patients, can be explored and examined.

The Codes states that nurses should be a model of integrity and leadership for others to aspire to. Leadership and role modelling forms an integral part of maintaining an effective organisational culture and encourages others to work to the values and beliefs that underpin 'the way things are done around here'.

\section{Introduction}

Organisational culture is a somewhat nebulous, but powerful concept reflecting the values and beliefs that underpin how the workplace operates. It is the "the way things are done around here". A number of high profile healthcare scandals in the United Kingdom (UK) have highlighted the strength of organisational culture in defining the quality of healthcare provision. This article explores the concept of organisational culture, its effect on healthcare delivery and some of the factors which can be used to improve its influence

\section{What is culture?}

When using the word 'culture' there is emphasis on the word as a noun, a person, place or thing. The online Oxford English Dictionary (2017) describe culture as 'the ideas, customs and social behaviour of particular people in society'. This reflects a way in which literature over the decades has described or defined it. However, when you look at how the word culture is used in Biology, it is a verb, an action word and is described as 'maintaining conditions suitable for growth' (Online Oxford English Dictionary, 2017). This description encapsulates both Health Education England (2017) programme to 'grow your own leaders' and West (2016) who suggests we need to create an environment in which staff can flourish. This suggests that we should be seeking to nurture a culture where conditions are suitable for growth and need to protect that culture whilst it is growing.

\section{What is Organisational Culture?}

Organisational culture is defined in numerous ways. It is referred to simplistically as 'the way things are done around here' by Watkins (2013), which sounds ritualistic. It infers that organisational culture is not accepting of change and that the culture is static rather than evolving. It implies that new people entering in to an organisation will continue to work in the existing way, rather than bringing new ideas and ways of working. Earlier literature includes 
descriptive words such as the attitudes, beliefs and behaviours of groups of people within organisations (Schien, 1985). Again, this description suggests a retrospective look of what an organisation is as opposed to a prospective view of the vision of the organisation. For the purposes of this article, organisational culture is described as the vision, values and behaviours of an organisation and the people within it.

\section{Time out 1.}

Consider Watkins (2013) phrase 'the way things are done around here'. Think of 2 different areas where you have worked. Consider 2-3 specific aspects of work undertaken in these 2 areas and the particular way they were carried out. What factors influenced how that were undertaken by staff? Think about job role boundaries and responsibilities, policies, procedures and rules. Which members of staff held the most influence in how things were 'done around here'? If you felt change was necessary, how easily do you think that could have occurred in each of the 2 work areas you have chosen?

\section{Why is organisational culture important?}

There is a perception that the culture within the NHS needs to be changed. This is evidenced by a number of high profile cases that have been detailed in the media. Culture is a common theme that emerges from the Francis Report (2013). Francis (2013) stated that organisational culture was a key determinant in what creates a safe healthcare system and that there needed to be a culture of openness and learning where staff were able to voice concerns. This implies that organisational culture is influential as it shapes the organisation in which we work. Having a shared organisational culture offers employees a sense of unity and understanding towards each other. In the context of healthcare, it offers a framework and a set of guiding values to create, implement and evaluate the delivery of the best possible care to patients, carers and staff. Thus, organisational culture is an important phenomenon as it can support or hinder the way in which an organisation performs. Many employees spend 37 hours a week in the organisation and as such, this needs to be an experience that is conducive to a healthy mind and body. If it is not then this could affect both employees work and home life. In the long term, this will affect individuals, teams, organisations and the NHS as a whole.

The NHS, as an entity, is a multi-faceted system in the respect that it is an interconnected series of smaller units where decisions and actions made in one unit can influence and impact on adjacent units. The NHS, as a whole system has developed 7 overarching core principles to which the whole system subscribes (Department of Health [DH], 2015). However, in such a 
large complex system these core principles need to be devolved and interpreted by individual organisations within the NHS, namely the NHS service providers. These providers will include, private and voluntary providers, GPs, Foundation Trusts and NHS Trusts. The individual service providers will further delegate these constituents from board level to frontline staff. As a member of an organisation, where one sits within that organisation will often determine how one engages with the organisational culture.

\section{Theoretical Frameworks}

There is a surfeit of types and theories of organisational culture, which consequently makes the notion of organisational culture a complex one. One such theory is Handy's 4 types of culture which consist of Power Culture, Role Culture, Task Culture and Person Culture (Handy, 1995). Handy (1995) describes the Power Culture as one where the power of decision-making is attributed to certain people. Role Culture is that where staff are delegated roles and responsibilities that are equivalent to their education, qualifications and areas of interest. Task Culture is concerned with generating teams who have a common interest to overcome problems and achieve targets. Person culture describes when employees have a greater sense of self-importance rather than the organisation. There is an understanding that these cultures are not isolated. An organisation can fluctuate in and out of each of the types described by Handy (1995) and that all four can coexist. The drivers of these types of cultures may be in response to a situation, a change in circumstances or personality types. Classifying a culture offers the potential to identify other contributing factors that compound the culture such as leadership style, organisational structure and performance. It enables people to make assumptions about work experiences and ethic of staff. There is no theoretical culture that is superior to another. However, the limitation of identifying and classifying organisations is that they then become categorised and people enter into them with preconceived ideas. This has the potential to exacerbate a negative culture.

Deal and Kenedy (1982) created a framework of six cultural elements that are the foundations of organisational culture. This was revised later by Johnson and Scholes (1992) who described 6 elements of a paradigm. The 6 elements of the paradigm included Stories which were events from the past that demonstrated what the organisation perceived as exceptional behaviour. This was followed by Ritual and Rites, which are terms for describing acceptable behaviours. Symbols are described as part of the paradigm and are visual representations of the organisation and would include corporate branding, uniforms and logos etc. Organisational structure generates the lines of power and influence. They describe Control Systems as these that have influence over finances, quality and rewards. This is followed by Power Structure, which relates to the key people in an organisation that have strategic vision and influence the 
decision-making (Johnson and Scholes, 1992). This paradigm is known as the Cultural Web. The cultural web is a way of looking at an organisation and how its perspectives or ideas are demonstrated. It offers a framework to assess the 6 elements and is used to identify areas of strength and weakness. It enables organisations to analyse where they are now and is used as a vehicle to drive an organisation to where it wants to be.

Looking at the theoretical concepts of what organisational culture is there is a notable absence of reference made to how culture integrates the human dimension. The theories refer to a strategic view, with a perceived hierarchy and established characteristics of an organisation. This theoretical concept is not synchronised with the perception of organisational culture within the NHS. Rather than compartmentalising Trusts into a cultural type, there is a positive drive to create a culture within the organisation that focuses on improving the quality of care delivered by learning lessons from the past. This appears to make the NHS unique in its approach to organisational culture.

\section{Time out 2}

Re-examine the six elements of the organisational culture paradigm described above. Can you give examples for each from your own work place? What do you think this tells you about your own workplace organisational culture?

\section{Organisational culture in practice}

Francis (2013) highlighted in the Mid Staffordshire Public Inquiry that there was misalignment of actions and behaviours demonstrated by staff that resulted in tragic failings in patient care. He specified in the report how staff were accepting of poor standard of care. He critically detailed how there was a toxic culture that focused on financial aspects of balancing the books and meeting targets and this was to the detriment of delivering safe patient care. To compound this further there was confusion regarding roles and responsibilities and a lack of accountability. From the staff working at the Trust there was a sense of fear and adverse repercussion if they spoke up, this inadvertently led to low morale and a lack of being open and transparent. This toxic culture had a negative impact on both patients, carers and staff within the organisation. This implies that organisational culture is an overarching element that if not driven by people with the right values and skills the negative impact can be catastrophic.

Organisational culture is a term used throughout literature, but for it to have meaning and relevance, it is important that staff and patients understand what it is, its significance and how 
it can affect patients, carers and staff. Organisational culture underpins numerous initiatives in terms of supporting creativity and innovation, driving change and improving the quality of care delivered to patients (Dawson \& Andriopoulos, 2014). NHS service providers generally have a mission statement with a number of values, which they collectively aspire to fulfil. The NHS core values and 7 principles reinforce the strategic vision set out by the NHS in their Five Year Forward view (NHS England, 2014). This vision sets out to ensure that the NHS service providers deliver the highest quality, compassionate care that is built on the quality principles of the NHS. In the NHS we strive to create a culture that gives staff the freedom and confidence to act in the interests of patients.

Within individual organisations, the vision of that organisation is clearly articulated and correlates to providing high quality care to patients to support the best possible outcomes. This vision is attained by demonstrating clear values such as teamwork, demonstrating compassion, having respect and integrity and being accountable and responsible for our actions. This determines that the NHS has a clear and definitive plan that has been recognised and implemented strategically. How this is then translated and achieved in clinical practice needs to be considered. The clear values of the NHS resonate the expectations of many professional bodies represented with the NHS (GMC, 2017, HCPC, 2016; NMC, 2015). This suggests that the culture within the organisation should be explicit; the values created by the NHS are a reinforcement of practitioner's professional values. These values should be visible to all and by extension the registered professional within NHS should be leading by example, demonstrating what these core values look like in everyday practice.

Every organisation has its own unique style of working which often contributes to its culture. The vision, values and behaviours of an organisation are the foundations that support organisational culture. The culture of a work place influences the way in which employees behave both within and outside of the organisation. The culture of an organisation gives it a sense of direction. Culture fundamentally effects the way in which we treat each other and our patients. However, having a set of core values, which a Trust has committed to, does not demonstrate that these are the lived experience of the staff and patients. The values that are explicitly stated need to be reflected in the way that staff and patients feel (Watkins, 2013).

\section{Organisational subcultures}

Surface level culture (that which is visible) is demonstrated by audible and visible patterns of behaviours, in contrast to the deeper level (that which is less visible) which are the values and behaviours that a group shares (Barr and Dowding, 2012). These norms establish the kind of behaviours that the group expect of each other. They are described as the learned values in 
respect of new people to the team or organisation learn the culture. This could potentially have both positive and negative connotations. A subculture may coexist interpedently with others or create conflict. Employees gradually learn what behaviours are acceptable. Organisational culture is important in the way that it influences the process of socialisation for team members and shapes organisational behaviours; it develops through social interaction (Barr and Dowling, 2012). On a micro level, when starting on a new ward or placement as the new person to the ward you will learn 'how things are done around here'. Patterns and norms of behaviour develop over time; however, these will influence the culture of the ward. It is easy to be influenced by others and Schein \& Schein (2017) suggests that people entering in to groups need to manage personal issues relating to the feeling of being included. This involves having an identity and being accepted. New recruits will look for confirmation that they 'fit in' and are demonstrating behaviours that are deemed correct and acceptable to others (Parkin, 2010). This infers individuals (usually the leader) have input into creating an emerging culture. Again, this could be a positive or a negative culture and this culture will have a direct effect on the patient and carers experience and on that of the staff. An example of a positive culture is one where staff feel that they have a voice, can speak up and raise concerns. This will have a positive impact on both staff and patients. Wards that clearly demonstrate mistakes are acknowledged, learnt from and which embrace a culture of learning will create and sustain a culture that is conducive to staff achieving the delivery of safe and effective care to patients in a supportive environment (Francis, 2013). In contrast, entering a ward where there are feelings of being powerless, scared or bullied due to the culture within that environment will lead to staff betraying their professional values by conforming to the culture or alternatively taking sick leave or ultimately leaving the profession. This details the significance of subcultures to organisational culture and the consequences in terms of impact on wards, Trusts and the NHS as a whole.

The above examples demonstrate the need for strong collective leadership that can drive organisational culture at departmental level to aspire to achieve the strategic vision, values and goals of an organisation. This would involve ensuring from the outset that staff recruited have the right values and skills to work in a healthcare organisation and that these staff a supported throughout their careers to maintain them.

\section{Time out 3.}

A subculture could be a smaller work area within the bigger organisational culture. This may be a ward or unit within the larger hospital, or a community practice area that is part of a much 
bigger group or organisation. What do you think are the factors that may create this cultural difference? Consider factors such as leadership within the bigger organisation and the smaller subculture or the values and beliefs of the staff within the subculture.

\section{Organisational culture and leadership}

The King's fund (2017) suggest that leadership is the biggest influential factor in creating a positive organisational culture. The concept of collective leadership is that everyone takes responsibility for the organisation depending on his or her expertise, capability and motivation. Leadership and organisational culture are terms that are inextricably linked. Leaders play an important part in establishing a clear sense of mission and direction (Robinson and TyndaleBircoe, 2012). Organisational culture needs to be meaningful, sustainable and have a clear sense of direction. Staff need to have a connection and understanding of the values that are the foundations of organisational culture. When we address leadership, we often describe the qualities of a great leader. Undoubtedly, these labels are positive and often include communication, teamwork, honesty, integrity and compassion. These words are not exclusive qualities of great leaders. These words describe the basic attributes that you would expect to see of professionals working within the NHS. They are not only qualities they are the values that we should strive to work towards at all times. This is why the concept of collective leadership makes sense. Leadership is not a title that is bestowed on the people in the higher echelons of the organisation and it is not a title prefixed to a job role. Leadership is what we do as individuals, the way in which we do it and how we encourage other people to undertake the journey with us. This reflects the concept that West (2014) describes when he suggests that every interaction at every level in an organisation shapes the emerging organisational culture.

\section{Time out 4.}

Consider a colleague who was senior to yourself and whose leadership you admired. Remember that leadership differs to management. A good leader can transmit a clear vision and direction; can motivate and energise the team; can facilitate change within the team, particularly during unsettling and difficult times. How do you think this favourite leader transmitted the values and beliefs of good healthcare delivery? Think about factors such as how they lived and role modelled those values, whether they welcomed discussion and ideas, and the respect he/she showed the staff. 


\section{Meaningful organisational culture}

The strategic vision and values that drive the organisational culture need to be values that are meaningful and that are clearly visible to patients and staff. They have to be more than 'just words'. Organisations (and staff within the organisation) need to be held to account for these values and have a responsibility to staff and patients to bring them to fruition. To be meaningful these values should be actioned. Organisational culture, to some extent is conducive with the 'corporate brand' of the individual NHS Trust. They are designed to have impact and for people to 'buy in' to the common values. Creating this dynamic vision is resource intensive both in terms of labour and financial resources, however that vision has to be realised by all. The positive and emotive words need to be enacted upon. This action will create the organisational culture, rather than the words. The words will give staff and patients an expectation and a foundation on which to evaluate their experience. The desired corporate values are often misaligned to the values in use, which are the values enacted through formal practice. The mission statement and core values of an NHS service provider need to be modelled from the Boardroom to the front line. It is important to staff that they can evidence the ways in which the core values are being demonstrated on the front line. It needs to be evident that the core values are not just corporate jargon.

Although the mission statement and the associated core values will be directed from Board level, it is imperative to the success of these values being respected and realised that staff are involved on creating the values from the outset (Robinson and Tyndale-Biscoe, 2012). The values should be a shared collaboration rather than values imposed and dictated; as such, they will be shared beliefs, attitudes and behaviours. Imposing values on staff that they have not been involved with creating could lead to resistance. Staff need to be engaged from the outset and two-way communication be evident throughout the creation, design and implementation phases. The mission statement and values need to clearly articulate the direction in which the organisation is moving, the understanding of how it is going to get there and a clear sense of aligning staff to this vision. Staff buy-in to the organisation mission and direction is important, without it, the mission not be achieved. Whilst the core values underpin the organisational purpose, there is a likelihood that most front line staff will concentrate on their individual departments. Staff will need to be supported in decision making when aspiring to meet the core values, but there also needs to be reinforcement of how their department contributes to the system wide organisation. To do this the core values need to be translated in to something meaningful and tangible. The core values have to evolve from a set of words to measurable actions and behaviours. 


\section{Time out 5.}

Do you know where to access the strategic vision and values of your overarching organisation? If you don't, take time to find and access the appropriate document, such as the strategic plan. Can you tease out and list the values from areas such as the mission statement? Do these match you own values and beliefs in how healthcare should be delivered?

Robinson and Tyndale-Biscoe (2012) detail a case study whereby a NHS Trust are using a table that clearly demonstrates what their values are and how this values is realised and what this will mean to patients and carers.

An example of this is detailed (fig 1.0) in relation to the value of being 'open and honest'. Figure 1.0

\begin{tabular}{|c|c|c|}
\hline $\begin{array}{l}\text { Value- what we } \\
\text { are }\end{array}$ & What do we do & How do we do it \\
\hline Open and honest & $\begin{array}{l}\text { Communicate in a timely and open manner } \\
\text { sharing relevant information with patients/carers } \\
\text { and staff }\end{array}$ & 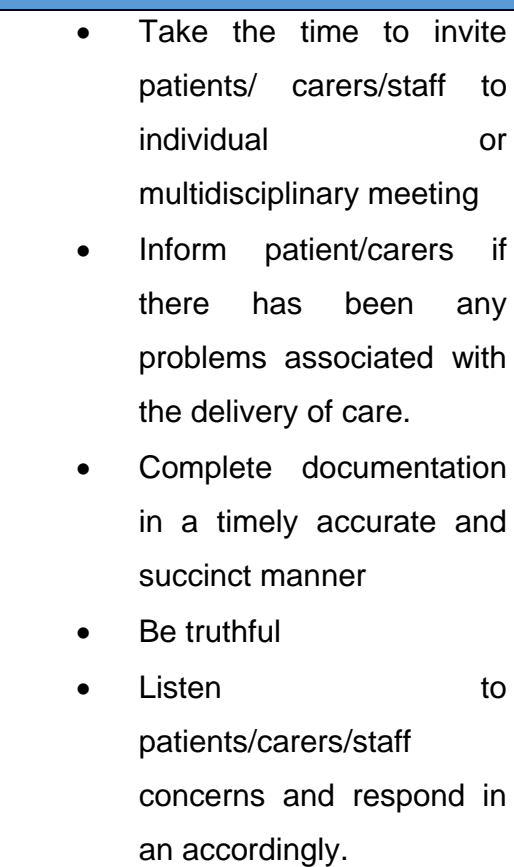 \\
\hline
\end{tabular}

The purpose of creating a mission statement and core values is to ensure a secure foundation on which the organisational culture can be built and sustained. Therefore, the cultural behaviours and beliefs need to be measured and evaluated to ensure that the organisational culture is being realised. Having tangible values will encourage evaluation. It is a process whereby meaningful data can be collected to recognise cultural issues, create strategies to strengthen a positive culture and to develop a cohesive individual and team approach; to 
achieving the strategic organisational values of the Trust (Robinson and Tyndale-Biscoe, 2012).

\section{Conclusion:}

The word culture is used as a suffix to many other words which describe the way in which we do things. When preceded by the word organisational it is intended to describe the vision, values and beliefs of the organisation and the people within it. For organisational culture to be achieved it requires a whole system approach, where individuals are encouraged to work collectively and collaboratively to create, implement and fulfil the aspirations of the organisation. This in turn creates the foundations on which to build a positive organisational culture that transcends all aspects of the organisation from the chief executives in the Boardroom to the frontline staff.

\section{Time out 6}

Nurses are encouraged to apply the four themes of The Code (NMC 2015) to their professional practice. Consider how knowledge of the role and influence of organisational culture in healthcare relates to The Code.

\section{Time out 7}

Now that you have completed the article, you might like to write a reflective account as part of your revalidation.

\section{References}

Barr J. and Dowding L. (2012) Leadership in Healthcare. London. Sage Publications.

Dawson P. \& Andriopoulos C. (2014) Change Management: a guide to effective implementation. $3^{\text {rd }}$ Edition. London. Sage Publications.

Deal T.E. and Kennedy A.A. (1982). Corporate Cultures: The Rites and results of Corporate Life. Reading. Addison-Wesley 
Department of Health $[\mathrm{DH}]$, 2015). Introduction to the NHS Constitution. https://www.gov.uk/government/publications/the-nhs-constitution-for-england/the-nhsconstitution-for-england [Accessed 18/09/17]

Francis R. (2013) The mid Staffordshire NHS Foundation Trust Public Inquiry http://webarchive.nationalarchives.gov.uk/20150407084003/http://www.midstaffspublicinquir y.com/ [Accessed 18/09/17]

General Medical Council (2017) Members Code of Conduct http://www.gmcuk.org/about/council/register code of conduct.asp [accessed 18/09/17]

Handy, C. (1995) Gods of Management, the changing work of organisations. Oxford. Oxford University Press

Health and Care Professions Council (2016) Standards of Conduct, Performance and Ethics http://www.hcpc-

uk.org/aboutregistration/standards/standardsofconductperformanceandethics/ [accessed 18/09/17]

Health Education England (2017) Grow your own leaders programme https://hee.nhs.uk/heeyour-area/east-england/news-events/news/grow-your-own-programme-shortlisted-hsjawards [Accessed 18/09/17]

Johnson G. (1987) Strategic change and the management process. Oxford. Blackwell Science

Johnson G. (2007) Replacing Corporate Strategy. New Jersey. Prentice Hall.

NHS England (2014) 'The NHS five year forward view' https://www.england.nhs.uk/wpcontent/uploads/2014/10/5yfv-web.pdf [Accessed 18/09/17]

Nursing and Midwifery Council (2015) The Code: Professional standards of practice and behaviour for nurses and midwives. https://www.nmc.org.uk/standards/code/ [Accessed 18/09/17]

Parkin P, (2010) Managing Change in Healthcare: using action research. London Sage Publications.

Robinson P. and Tyndale- Bircoe J. (2012) 'What makes a top Hospital' Organisational Culture. www.tophospitals.co.uk. [Accessed 18/09/17]

Schein E.H (1985). Organisational culture and leadership. $1^{\text {st }}$ Edition. New Jersey. Josey Bass 
Schein E.H and Schein P. (2017) Organisational leadership and culture. $5^{\text {th }}$ Edition. New Jersey. Wiley and Sons.

The Oxford English Dictionary (2017) https://en.oxforddictionaries.com/definition/culture [accessed 18/09/17]

Watkins MD (2013) What is organisational culture and why do we need it? https://hbr.org/2013/05/what-is-organizational-culture [Accessed 18/09/17]

West M. (2014) Collective and inclusive NHS leadership is the only way forward. Accessed https://www.leadershipacademy.nhs.uk/blog/collective-and-inclusive-nhs-leadership-is-theonly-way-forward/ [Accessed 18/09/17]

West M. (2016) Creating a workplace where NHS staff can flourish https://www.kingsfund.org.uk/blog/2016/01/creating-workplace-where-staff-can-flourish [Accessed 18/09/17] 